Sonja Filipović-Kovačević

UDC $81: 659$

Filozofski fakultet Univerziteta u Novom Sadu

sonjaf@eunet.rs

Originalan naučni rad

\title{
KONSTRUISANJE ZNAČENJA U INDIREKTNOJ KOMUNIKACIJI: EMPIRIJSKI PRISTUP ${ }^{1}$
}

Ovaj rad predstavlja primenjeno kognitivnolingvističko istraživanje gde se ispituje mentalni proces konstruisanja značenja koji se odvija u umu primalaca poruke $u$ procesu komunikacije. Predmet istraživanja su reklame u kojima je primenjen poseban tip blaže reklamne strategije, a koji podrazumeva spajanje logički nespojivih pojmova. Cilj istraživanja je eksperimentalno ispitati kako primaoci poruke dolaze do implicitno izraženog značenja u reklamama. U tu svrhu sproveden je eksperiment s jednom reklamom u kome ispitanici pokušavaju da objasne do koje poruke su došli i na koji način. Odgovori ispitanika su analizirani tako što je utvrđeno sledeće: a) jezički i vizuelni elementi koji su podstakli ispitanike na razmišljanje u određenom smeru, b) načini na koje su dati elementi prošireni $\mathrm{u}$ određene scenarije na osnovu vanjezičkog iskustva, kao i c) analogije između logički nespojivih elementata u reklami. Pošlo se od pretpostavke da je kognitivni mehanizam pojmovne integracije $u$ osnovi interpretacije značenja, te je teorija pojmovne integracije primenjena na protumačene rezultate dobijene u eksperimentu.

Ključne reči: indirektno reklamiranje, komunikacija, konstruisanje značenja, pojmovna integracija

\section{UVOD}

Najopštije rečeno, ovaj rad predstavlja primenjeno kognitivnolingvističko istraživanje, u kojem se ispituje mentalni proces konstruisanja značenja koji se odvija u umu primalaca poruke. Cilj istraživanja je eksperimentalno ispitati kako primaoci poruke dolaze do indirektno izraženog značenja u reklamama. Ovde se misli na utvrđivanje mentalnog procesa odgovornog za "otpakivanje" uvijenih reklamnih

1 Rad je rađen u okviru projekta broj 178002 Jezici i kulture u vremenu i prostoru, koji finansira Ministarstvo prosvete i nauke Republike Srbije. 
poruka. Da bi se postavio okvir za istraživanje trebalo bi razjasniti dva pitanja: a) Zašto proučavati indirektnu komunikaciju i to u vezi s reklamiranjem? i b) Zašto koristiti teorijski okvir kognitivne lingvistike?

Prvo, indirektna komunikacija, koja se zasniva na implikaturi, tj. saopštavanju više od onoga što je rečeno (Yule 1996: 35-36), ukazuje na kreativnost ljudskog uma i na značaj nejezičkog, enciklopedijskog znanja prilikom interpretiranja poruka. Drugo, reklamiranje, kao sredstvo obaveštavanja radi prodaje (Džefkins 2003: 21), je fenomen tipičan za moderno potrošačko društvo, što istraživanje u ovom polju čini aktuelnim. Pored toga, mnoga istraživanja u oblasti reklamiranja pokazuju da danas preovlađuje indirektni reklamni tip ili reklamiranje s blažom reklamnom strategijom² $^{2}$ (Cook 2001: 15), gde se primenjuje suptilno pružanje informacija o predmetu reklamiranja bez otvorenog naglašavanja njegovih prednosti. Ovakve reklame obiluju metaforama, metonimijama, analogijama, kontrafaktivima, igrama rečima, kako pokazuju razne studije (Ward i Gaidis 1990, Leigh 1994, Forceville 1996, McQuarrie and Phillips 2005, van Mulken et. al 2005, ...).

$\mathrm{U}$ ovom radu u središtu interesovanja su reklame u kojima je primenjen poseban tip blaže reklamne strategije, koji podrazumeva spajanje logički nespojivih pojmova. U pitanju su reklame poput sledećih. U reklami za pranje posuđa u naslovu stoji: "Osuđeni na posuđe? Više ne”. Pri tome, umesto slova O stoje lisice za hapšenje. Ovde se u vezu dovode pranje sudova i robijanje. U reklami za bankarski transfer novca stoji: "Siguran put do odredišta". Na slici je predstavljen tabak novčanica od 10 evra vezan sigurnosnim pojasom. Ovde novac putuje kao čovek, avionom, vezan sigurnosnim pojasom, što je nelogično. Ovakve reklame svojom neobičnošću intrigiraju i privlače pažnju primalaca poruka, te je kod njih poseban akcenat na prvim dvema fazama u osnovnoj formuli uspešnog reklamiranja AIDA (attentioninterest-desire-action): privući pažnju potencijalnih kupaca, zainteresovati ih, stvoriti im želju za proizvodom i nagnati ih na delovanje, tj. kupovinu (Strong 1925).

Predmet istraživanja u ovom radu je način na koji primaoci reklamnih poruka u ovakvim reklamama dolaze do nameravanog značenja. Drugim rečima, akcenat je na otkrivanju procesa konstruisanja značenja prilikom razumevanja reklamnih poruka. Kao teorijski okvir odabran je kognitivnolingvistički pristup budući da je kognitivna

2 Cook (2001: 15) razlikuje dve strategije u reklamiranju: žešću (eng. hard-selling) i blažu reklamnu strategiju (eng. soft-selling). 
lingvistika interdisciplinarno naučno polje koje izučava vezu između jezika i uma, te pokušava utvrditi i predstaviti kroz modele šta se dešava u ljudskom umu pomoću jezika, kao spoljašnje manifestacije mentalnih procesa. Stoga, ova grana lingvistike posebno je pogodna za predstavljanje mentalnog procesa interpretiranja poruka.

Cilj istraživanja u ovom radu je pokazati na konkretnom primeru reklame na koji način primaoci poruke koriste date zbunjujuće jezičke i/ili vizuelne signale $u$ reklamama, na koji način proširuju pojmove pomoću svog enciklopedijskog znanja, i kako uspostavljaju veze između logički nespojivih elementata radi konačnog shvatanja poruke. Polazi se od hipoteze da je kognitivni mehanizam pojmovne integracije u osnovi ovog procesa interpretacije, te se to nastoji i pokazati.

Dosadašnja kognitivistički orijentisana istraživanja reklamiranja uglavnom su teorijske prirode utoliko što autori primenjuju teorijske konstrukte pojmovne metafore, metonimije i integracije prilikom interpretiranja različitih jezičkih i vizuelnih fenomena (npr. Forceville 1996, Lundmak 2005, Ungerer 2000, Ruiz de Mendoza Ibáňez 2006). Ovaj rad se zasniva na empirijski dobijenim podacima, te predstavlja jedan dodatak malom broju eksperimentalnih kognitivnolingvističkih istraživanja reklama. Ovog tipa je rad autora Thibodeau i Durgin (2008), u kome se dokazuje da konvencionalne metafore mogu olakšati razumevanje novih metafora kada se obe odnose na isti pojam-sredstvo, i rad autora Joy, Sherry i Descenes (2009), u kome se razvijaju različiti tipovi mreža integracije u reklamama na osnovu konkretnih odgovora ispitanika.

\section{TEORIJSKI OKVIR: POJMOVNA INTEGRACIJA}

U kognitivnoj semantici smatra se da je značenje enciklopedijsko, i da je, kao takvo, sadržano u pojmovima, a da je jezik samo indikator za aktiviranje različitih pojmovnih operacija i vanjezičkog znanja radi konstruisanja značenja (Evans i Green 2006: 157-163). Dakle, značenje treba konstruisati, i to tako što se izvode zaključci na osnovu pojmovnih struktura, njihove organizacije, kao i vanjezičkog znanja.

Jedna teorija u okviru kognitivne semantike posebno se bavi dinamičkim konstruisanjem značenja. U pitanju je teorija pojmovne integracije (eng. Conceptual Integration/Blending Theory) (Fauconnier i Turner 2002), koja tvrdi da je pojmovna integracija osnovna kognitivna operacija u ljudskom razmišljanju. 
Najkraće rečeno, konstruisanje značenja podrazumeva specifičnu integraciju nove, novonastale strukture, koja je više od zbira njenih pojedinačnih delova. Iako je ova teorija prvobitno nastala da bi objasnila kreativne aspekte konstruisanja značenja, kao što su nove metafore i kontrafaktivi, sada se smatra da pojmovna integracija nije egzotična operacija, već osnovni mehanizam u ljudskom razmišljanju i zamišljanju.

Ovaj model razmišljanja operiše sa specifičnim preslikavanjima i projekcijama između više mentalnih prostora, pojmovnih jedinica sa elementima i međusobnim odnosima koji se stvaraju radi lokalnog razumevanja i delovanja (Turner i Fauconnier 1995: 184). Javljaju se najmanje četiri mentalna prostora: najmanje dva ulazna prostora (eng. input spaces), jedan amalgamski prostor (eng. blended space), koji sadrži selektivne i parcijalne projekcije elemenata i odnosa iz ulaznih prostora, koji se integrišu na takav način da proizvode novu, novonastalu strukturu (eng. emergent structure), koja kao takva ne postoji ni u jednom od ulaznih prostora. Konačno, postoji generički prostor (eng. generic space), izrazito apstraktna, shematska struktura koja obuhvata sve ostale pomenute mentalne prostore, poput zajedničkog sadržatelja, te omogućava njihovu integraciju. Da bi otpočeo proces pojmovne integracije, neophodno je da se prvo uspostave preslikavanja (eng. mappings), tj. odnosi ekvivalencije, između elemenata u ulaznim prostorima. Preslikavanja se mogu zasnivati na različitim tipovima odnosa kao što su istovetnost, vreme, prostor, transformacija, promena, sličnost, analogija, metafora, metonimija (posebno odnosi: uzrok-posledica i deo-celina), i na drugim ključnim odnosima (detaljno o ovome vidi u Fauconnier i Turner 2002: 92-102). Potom se određeni elementi i odnosi iz ulaznih prostora projektuju u amalgamski prostor, u zavisnosti od konkretnog konteksta u kome se odvija komunikacija. Proces pojmovne integracije često se grafički predstavlja pomoću dijagrama, pri čemu su mentalni prostori naznačeni kao krugovi, elementi i odnosi tačkama, međuprostorna preslikavanja kao pune linije između mentalnih prostora, dok su projekcije iz generičkog prostora u ulazne prostore, kao i projekcije iz ulaznih prostora $\mathrm{u}$ amalgamski prostor predstavljene isprekidanim linijama (vidi dijagram 1): 


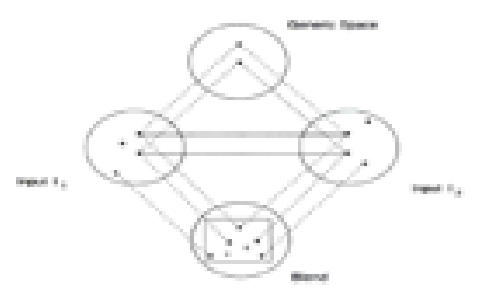

Dijagram 1: Osnovna mreža pojmovne integracije (iz Fauconnier i Turner 2002: 46)

Proučavani kognitivni mehanizam biće opisan na primeru nove reči $\mathrm{u}$ srpskom jeziku pica-burek, u značenju burek s nadevom koji se tipično stavlja na picu (šunka, sir, pečurke, kečap), te je u nekom smislu istovremeno i burek i pica (primer preuzet iz Filipović-Kovačević 2011: 252).

Uspostavljaju se preslikavanja između elemenata u ulaznim prostorima pica i burek, a na osnovu generičkog prostora koji obeležava hranu s nadevom: okruglo, nemasno, pljosnato testo - masno testo od zgužvanih kora, nadev: šunka, sir, pečurke, kečap (odgore) - nadev: sir, meso ili krompir (u testu). U amalgamski prostor projektuje se semantički okvir iz ulaznog prostora burek, jer se radi o hrani s masnim testom od izgužvanih kora s nadevom u samom testu, dok se iz ulaznog prostora pica projektuje sam nadev šunka, sir, pečurke, kečap, te i takav ukus. Picaburek je pojmovni amalgam nastao kao rezultat projekcija u amalgamski prostor iz dva ulazna prostora; jedan se odnosi na tipičan burek, a drugi na tipičnu picu. Tako je nastali amalgam istovremeno i burek i pica (tj. burek s nadevom za picu)

\section{EKSPERIMENT}

Cilj sprovedenog istraživanja je utvrditi na koji način ispitanici dolaze do implicitno izraženog značenja u reklamama, koje se izražava zbunjujućim, nelogičnim kombinacijama jezičkih i/ili vizuelnih signala. Polazi se od hipoteze da je glavni mehanizam za rekonstruisanje poruke pojmovna integracija, te se ova hipoteza pokušava potvrditi na osnovu odgovora ispitanika. Istraživanje je sprovedeno u formi fenomenoloških intervjua, pri čemu su odgovori dati u pisanoj formi. 


\subsection{METODOLOGIJA}

Ispitanici su 20 studenata na prvoj godini Odseka za anglistiku na Filozofskom fakultetu Univerziteta u Novom Sadu. Njihovo učešće u eksperimentu je bilo dobrovoljno. Svi su maternji govornici srpskog jezika.

Materijal čini jedna reklama koja je namerno odabrana tako da zadovolji sledeće kriterijume: a) na srpskom jeziku je - to je maternji jezik ispitanika, te se isključuje mogućnost pogrešne interpretacije usled jezičke barijere; b) odražava indirektnu strategiju komunikacije u kojoj se kombinuju logički nepovezani elementi; c) veza između ovih logički nespojivih elemenata je metaforička, ${ }^{3}$ i d) vizuelni element je kompaktni vizuelni amalgam, gde su logički nespojivi elementi na slici potpuno integrisani u jednu celinu (o tipovima vizuelnih amalgama vidi detaljno $\mathrm{u}$ Filipović-Kovačević 2010: 140-143); to je važno, jer se polazi od pretpostavke da sama slika olakšava i ubrzava kognitivni proces interpretacije. Odabrana reklama promoviše Banku Intezu, tj. uslugu štednje. U naslovu stoji: "Idealno mesto za rast vašeg novca". Slika prikazuje službenicu koja meri ogromnu novčanicu od 100 evra naslanjajući je na dečiji metar za merenje visine u obliku žirafe; novčanica doseže visinu od $100 \mathrm{~cm}$, a službenica pokazuje na $120 \mathrm{~cm}$, tj. na njen potencijal rasta.

Samom izvođenju eksperimenta prethodila je priprema. Naime, stvorena je atmosfera u kojoj su ispitanici bili zainteresovani i podstaknuti na razmišljanje i diskusiju o reklamiranju. Pokazane su im dve reklame u kojima su spojeni logički nespojivi pojmovi, a zadatak ispitanika bio je da razmisle o tome da li su im reklame interesantne, da objasne koje su reklamne poruke, kao i kako su do njih došli. Ovo je bilo osnov za pitanja na koja je trebalo samostalno da odgovaraju u eksperimentu. Da bi se izbegla anksioznost, bilo je izuzetno važno uveriti ih u to da je upitnik anoniman, da nema tačnih i netačnih odgovora, kao i da se ispituje samo njihov proces razmišljanja. Eksperiment je sproveden u formi fenomenoloških upitnika u kojima su ispitanici trebali da odgovore na sledeća tri pitanja što preciznije, pri čemu im je rečeno da uzmu u obzir kako jezik tako i sliku:

(1) Koja je poruka, tj. značenje, reklame?

(2) Kako ste došli do značenja?

(3) Šta je neobično u reklami? 


\section{REZULTATI EKSPERIMENTA}

Tabela 1 prikazuje rezultate dobijene nakon analize odgovora ispitanika. $\mathrm{U}$ njoj je zabeležen broj ispitanika koji su uočili i u svojim odgovorima naveli sledeće elemente: novčanicu, vrednost novca, banku, dete, metar, žirafu, i radnje ili odnose: štednju, fizički rast, uvećavanje količine i vrednosti, kao i uočene analogije između navedenih elemenata i odnosa: novac i dete, novac i žirafa, fizički rast i uvećanje količine i vrednosti.

\begin{tabular}{|l|l|}
\hline ELEMENTI I ODNOSI & BROJ ISPITANIKA \\
\hline novčanica (evro) & 17 \\
\hline $100,120 \mathrm{E}$ & 3 \\
\hline banka & $5(\rightarrow 20)$ \\
\hline štednja & $1(\rightarrow 20)$ \\
\hline deca & 10 \\
\hline fizički rast & 7 \\
\hline metar & 6 \\
\hline žirafa & 7 \\
\hline žirafa kao metar & 5 \\
\hline novac - dete & 7 \\
\hline fizički rast - uvećanje & 6 \\
\hline fizički rast novca & 14 \\
\hline
\end{tabular}

Tabela 1: Odgovori ispitanika

Nakon analiziranja odgovora na pitanje koja je poruka reklame, izvedeni su sledeći zaključci. Devetnaest ispitanika razumelo je nameravano značenje: "Novac na štednji u Banci Intezi uvećaće se po povoljnoj kamatnoj stopi, tj. profitiraćete". ${ }^{4}$ Pored ovakve najopštije interpretacije neki ispitanici su se usredsredili na različite aspekte štednje:

- pet ispitanika naglasilo je da je uvećanje novca sigurno. Na primer: "Banka Inteza je idealno mesto gde će vaš novac sigurno rasti”;

- jedan ispitanik ukazao je na to da je kamatna stopa dobra: Na primer: "Novac

4 Jedan ispitanik nije razumeo poruku na odgovarajući način, te je rekao: "Ljudi vole novac, mnogo novca". 
ostavljen na štednju u ovoj banci će "porasti" zahvaljujući kamati koja je vrlo povoljna i privlačna za klijente";

- $\quad$ šest ispitanika je pažnju usmerilo na samu banku tvrdeći da je ona idealno mesto za štednju. Na primer: "Banca Intesa je idealno mesto za štednju";

- dva ispitanika uporedila su ovu banku sa drugim bankama tvrdeći da je ova bolja ili najbolja. Na primer: "Štednja u ovoj banci je najbolja”.

Nakon analiziranja odgovora na pitanja kako ste došli do značenja reklame i šta je neobično ili nespojivo u reklami, izvedeni su sledeći zaključci. Ispitanici su uočili određene elemente i njihove međusobne odnose na sledeći način. Prepoznali su dva različita i, na prvi pogled nepovezana, niza elemenata u određenim odnosima, tj. dva scenarija, koji su neophodni za interpretaciju poruke. Jedan scenario se odnosi na novac, a drugi na decu. Što se tiče scenarija koji se odnosi na novac, sedamnaest ispitanika je pomenulo novčanicu, od kojih je 3 pomenulo njene konkretne vrednosti, 100 i 120 evra. Banku je pomenulo pet ispitanika, a štednju jedan. Međutim, u odgovoru na prvo pitanje, gde su ispitanici interpretirali značenje reklamne poruke, banku, štednju i uvećanje novca pomenulo je devetnaest ispitanika, te je očigledno da su u odgovorima na drugo i treće pitanje podrazumevali da se zna na šta misle (na banku i uslugu štednje). Ovo su neki od autentičnih odgovora: "Novčanica od 100 evra koja "postaje" novčanica od 120 evra je veoma jasna slika"; "Tako i klijenti ove banke mogu uvećati novac"; "Banca Intesa je idealno mesto za otvaranje štednog računa i štednju".

Interesantno je primetiti da su svi ispitanici prepoznali metonimijsku vezu između papirne novčanice i novca, bilo automatski pominjući novac, a ne novčanicu: "Novac se meri metrom baš kao i deca", bilo izjednačavajući ih verbalno: “... i meri taj rast novčanice, tj. novca koji štedite", ... "jer novac (novčanica), tj. količina novca na računu".

Što se tiče scenarija u vezi s decom, deset ispitanika je pomenulo decu, rekavši da ona rastu. Interesantno je da su neki ispitanici pomenuli određene karakteristike u vezi s rastom dece, kao što su: deca rastu stalno; rastu brzo, potrebni su im dobri uslovi, pažnja, sigurnost, briga; rast dece se kontroliše. Jedanaest ispitanika pomenulo je metar za merenje visine u obliku žirafe, dok je njih sedam pomenulo samu žirafu, kao životinju, pri čemu su joj pripisali visinu kao ključnu karakteristiku. Ovo su neki od ilustrativnih odgovora: "Zbog toga što su upotrebili metar za merenje visine dece, 
koja brzo rastu"; "Deci treba sigurnost ..."; "Na slici je žirafa, što označava rast, nešto visoko. Tu je metar, dečiji, pomoću čega merimo visinu dece, što označava neku sigurnost."

Posebno je interesantno uočiti način na koji su ispitanici uočili i uspostavili veze između dva različita scenarija. Prepoznali su analogije između elemenata koji pripadaju različitim scenarijima, između novca i dece (sedam ispitanika), kao ifizičkog rasta i uvećanja (šest ispitanika). Sledeći autentični odgovori ilustruju rečeno:

Novac = dete: "Službenica drži novčanicu kojoj meri visinu. Samim tim, novčanica je upoređena sa detetom, čiji se rast kontroliše" ; "Novac se meri metrom baš kao i deca, koja stalno rastu”; "Tako što se novčanica, isto kao i dete, meri koliko je porasla"; "Oni se prema njihovom novcu odnose pažljivo kao prema deci".

Rasti (fizički) = uvećati se (količinski): “... jasno ukazuju da je naglasak na rastu te novčanice, što je u prevodu uvećanje novca"; "To znači da bi naš novac brzo narastao, $t j$. da bi mu se povećala količina, jer i deca brzo rastu"; "Neobično je da povećanjem same novčanice može rasti i vrednost koju ima”; “... jer ako se već govori o "rastu novca" nije bukvalno u visinu, nego u količini".

$\mathrm{U}$ odgovorima ispitanika u kojima se novac povezuje s decom dominiraju poredbeni izrazi: biti upoređen sa, baš kao i, isto kao i, prikazivati kao, dok oni u kojima se uvećanje dovodi u vezu sa fizičkim rastom, dominira izraz: to jest ( $t j$.).

Konačno, četranaest ispitanika je pomenulo logički nemoguću situaciju u kojoj novac fizički raste, te tako dobija veću vrednost, što je u reklami veoma duhovito predstavljeno vizulenim sredstvima.

Važno je naglasiti da su navedeni i brojčano iskazani odgovori ispitanika utemeljeni na eksplicitno datim odgovorima ispitanika. Stoga, prilikom analiziranja dobijenih rezultata moraju se uzeti u obzir sledeći faktori u vezi s ispitanicima: (1) motivisanost, (2) stepen podrazumevanja, (3) svesnost. Prvo, neki od ispitanika su verovatno bili više, a neki manje zainteresovani da se angažuju da obave postavljeni zadatak. Drugo, ispitanici su sigurno nešto podrazumevali, te smatrali da ne treba eksplicitno izraziti (na primer, da se radi o bankarskoj usluzi štednje). Treće, neki ispitanici verovatno nisu u potpunosti svesni svih koraka u svom načinu rezonovanja.

\section{ZAKLJUČNA RAZMATRANJA}

Sprovedeni eksperiment i autentični odgovori ispitanika na tri postavljena 
pitanja mogu poslužiti kao smernice za stvaranje mreže pojmovne integracije kao moguć model za mentalne procese angažovane prilikom traganja za najverovatnijim značenjem indirektnih reklamnih iskaza. Opšta mreža pojmovne integracije koja je predstavljena u odeljku 2 ovde će biti popunjena eksperimentalno dobijenim podacima važnim za konstruisanje značenja u reklami za štednju u Banci Intezi (svi autentični odgovori ispitanika dati su u tabeli 2 u dodatku; interpretacija rezultata dobijenih na osnovu eksperimenta predstavljena je u odeljku 4).

Ispitanici su uspostavili dva ulazna mentalna prostora, tj. dva logički nespojiva scenarija. Jedan od njih odnosi se na decu i sadrži sledeće elemente i odnose: decu, koja rastu (od 100 do $120 \mathrm{~cm}$ ), i to rastu brzo, kontinuirano, neminovno; rast im se prati, tj. mere ih metrom za merenje visine u obliku žirafe; žirafa je visoka, ili najviša životinja i ima dugačak vrat. Uslovi za normalan razvoj dece su: briga, sigurnost, pažnja. Drugi ulazni mentalni prostor odnosi se na novac i sadrži sledeće elemente, odnose i karakteristike koje su im pripisane na osnovu enciklopedijskog znanja: novčanica, tj. metonimijski predstavljen novac, je u Banci Intezi, na štednji, tu je i određena kamatna stopa; novac, shodno tome, uvećava se od 100 do 120 evra tokom određenog perioda.

Ispitanici su povezali ova dva logički nespojiva scenarija iz dva ulazna prostora, $\mathrm{tj}$. uspostavili su sledeća međuprostorna preslikavanja: između dece i novca uočili su odnos istovetnosti na osnovu personifikacije, ili drugačije rečeno, na osnovu pojmovne metafore NEŽIVO JE ŽIVO (Lundmark 2005: 160, 173, 175, 179). Takođe, uočili su vezu između fizičkog rasta i uvećanja na osnovu pojmovne metafore višE JE GORE (Lakoff, Espenson, Goldberg, Schwartz 1991: 62). Prvopomenuta veza istovetnost je, prema odgovorima ispitanika, motivisana slikom, jer je papirna novčanica upotrebljena tamo gde bismo očekivali da vidimo dete, $\mathrm{tj}$. $\mathrm{u}$ kontekstu merenja visine dečijim metrom.

Proces konstruisanja značenja nastavlja se tako što se uočeni elementi i odnosi iz ulaznih prostora selektivno projektuju u amalgamski prostor. Prema odgovorima ispitanika, u ovom slučaju to izgleda ovako. Novac i deca se projektuju na jedan element $\mathrm{u}$ amalgamski prostor, $\mathrm{tj}$. metaforički su stopljeni ili izjednačeni. Lokacija, tj. banka, projektuje se iz ulaznog prostora novac. Odnos uvećanje takođe se projektuje iz pomenutog ulaznog prostora, dok se uslovi: brižan tretman, sigurnost i pažnja, kao i karakteristike dečijeg rasta: brzo, kontinuirano, neminovno, projektuju iz prostora 
deca i pripajaju se uvećanju u amalgamskom prostoru. Konačno, u amalgamskom prostoru javlja se novonastalo značenje: 'Novac u Banci Intezi će sigurno se uvećati kontinuirano i brzo; što se tiče načina na koji u Banci Intezi vode računa o novcu, novac je na sigurnom'. Pojmovna integracija za reklamu Banke Inteze predstavljena je na dijagramu 2 :

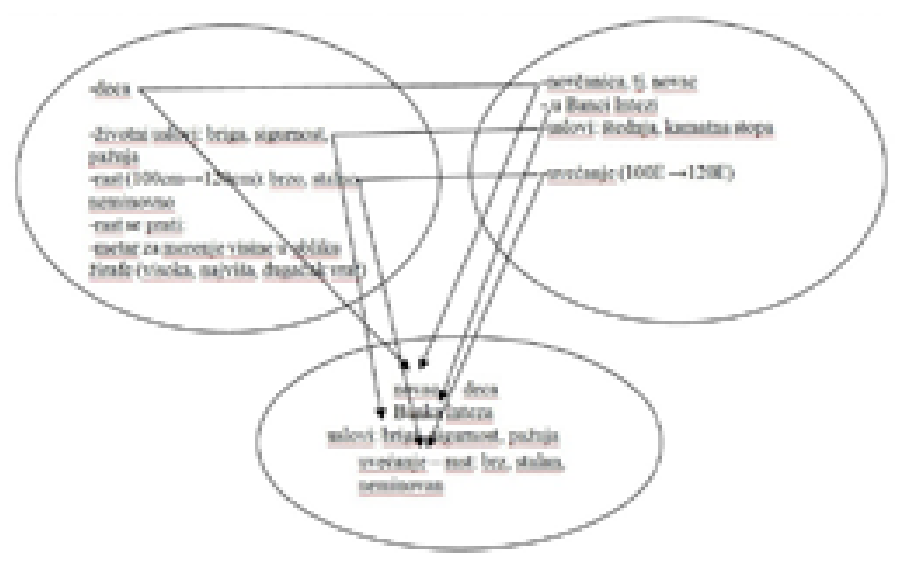

Dijagram 2: Pojmovna integracija u reklami za Banku Intezu

$\mathrm{Na}$ kraju, na osnovu dobijenih odgovora ispitanika u sprovedenom eksperimentu, može se zaključiti da reči i slike upotrebljene u reklami služe primaocima poruke kao signali koje oni dalje razrađuju u određene scenarije, a na osnovu svog vanjezičkog znanja. Na primer, u reklami ne piše kako deca rastu, ali ispitanici znaju da ona rastu brzo i neminovno, te da su za pravilan rast i razvoj neophodne briga i posvećenost. Takođe, $u$ reklami ne piše da se u banci novac štedi pod određenom kamatnom stopom, ali primaoci poruke znaju da je jedna od bankarskih usluga upravo štednja, i da uvećanje novca podrazumeva određenu kamatnu stopu. Stoga, ovo pilot istraživanje nagoveštava da primaoci reklamnih poruka na licu mesta na osnovu datih jezičkih i vizuelnih elemenata, uz svest o svrsi reklamiranja, kao žanra koji uvek ističe pozitivne osobine predmeta reklamiranja radi prodaje, stvaraju i ukrštaju na specifičan način najverovatnije scenarije koji dovode do najverovatnijeg nameravanog značenja, ili, drugim rečima automatski posežu za mehanizmom pojmovne integracije. Važno je naglasiti da je ovo istraživanje čiji je akcenat na procesu razumevanja indirektno izraženih poruka pilotskog karaktera, 
te kao takvo daje smernice za teorijsko razumevanje mehanizma razumevanja, kao i za dalja istraživanja u toj oblasti. Konačan zaključak o tome kako teče proces razumevanja zahtevao bi opsežnu analizu koja bi obuhvatala posebno osmišljene testove za dobijanje podataka od ispitanika o njihovim mentalnim procesima. Ovakvo istraživanje bi sigurno pokazivalo varijacije u dobijenim rezultatima, a pojmovna integracija bi verovatno bila jedan od važnih mentalnih procesa interpretacije.

\section{LITERATURA}

Cook, G. (2001). The Discourse of Advertising. 2nd edition. London, New York: Routledge.

Džefkins, F. (2003). Oglašavanje. Preveli: S. Stefanov, O. Popović, U. Vasiljević i Đ. Trajković. Beograd: Clio.

Evans, V., Green, M. (2006). Cognitive Linguistics. An Introduction. Edinburgh: Edinburgh University Press Ltd.

Fauconnier, G. and Turner, M. (2002). The Way We Think. Conceptual Blending and the Mind's Hidden Complexities. New York: Basic Books.

Filipović-Kovačević, Sonja. (2010). Vizuelni amalgami u kulturi modernog reklamiranja. U: Lj. Subotić i Živančević-Sekeruš (ur.). Susret kultura. Zbornik radova. Knjiga 1. Filozofski fakultet, Novi Sad. 135-145.

Filipović-Kovačević, Sonja. (2011). Anglicizmi kao međujezički pojmovni amalgami. Zbornik Matice srpske za filologiju i lingvistiku. Matica srpska, Novi Sad. LIV/2: 249-265.

Forceville, C. (1996). Pictorial Metaphor in Advertising. London, New York: Routledge.

Joy, A., Sherry, Jr. and Deschenes, J. (2009). Conceptual Blending in Advertising. Journal of Business Research. 62(1): 39-49.

Lakoff, G., Espenson, J., Goldberg, A. and Schwartz, A. (1989/1991). Master Metaphor List. Second Draft Copy. Berkeley: University of California. http://araw. mede.uic.edu/ alansz/metaphor/METAPHORLIST.pdf

Leigh, J. H. (1994). The Use of Figures of Speech in Print Ad Headlines. Journal of Advertising. 23: 17-34.

Lundmark, C. (2005). Metaphor and Creativity in British Magazine Advertising. Luleå: Luleå University of Technology, Department of Languages and 
Culture.

McQuarrie, E. F. and Phillips, B. J. (2005). Indirect Persuasion in Advertising: How Consumers Process Metaphors Presented in Pictures and Words. Journal of Advertising. 34/2: 7-21.

Mulken van, M., R. van Enscjot-van Dijk, H. Hoeken (2005). Puns, Relevance and Appreciation in Advertisements. Journal of Pragmatics. 37: 707-721.

Ruiz de Mendoza Ibáňez, F. J. (2006). The Role of Metaphor, Metonymy, and Conceptual Blending in Understanding Advertisements: The Case of Drugprevention Ads. Revista Alicantina de Estudios Ingleses. 19: 169-190.

Strong, E. K. Jr. (1925). Theories of Selling. Journal of Applied Psychology. 9/1: 75-86.

Thibodeau, T. and Durgin, F. H.(2008). Productive Figurative Communication: Conventional Metaphors Facilitate the Comprehension of Related Novel Metaphors. Journal of Memory and Language. 58/2: 521-540.

Turner, M. and Fauconnier, G. (1995). Conceptual Integration and Formal Expression. Metaphor and Symbolic Activity. 10/3: 183-204.

Ungerer, F. (2000). Muted Metaphors and the Activation of Metonymies in Advertising". In: A. Barcelona (ed.). Metaphor and Metonymy at the Crossroads. A Cognitive Perspective. Berlin, New York: Mouton de Gruyter. 321-340.

Ward, J. and Gaidis, W. (1990). Metaphor in Promotional Communication: A Review of Research on Metaphor Comprehension and Quality. In: Advances in Consumer Research. Vol. 17: 636-642.

Yule, G. (1996). Pragmatics. Oxford, New York: Oxford University Press.

Sonja Filipović-Kovačević

MEANING CONSTRUCTION IN INDIRECT COMMUNICATION: EMPIRICAL APPROACH

\section{Summary}

This paper is an applied cognitive linguistic research into the mental process of meaning construction taking place in the minds of message recipients in the communication 
process. The object of research are advertisements in which a special type of indirect, softselling advertising strategy is used; this strategy involves associating logically unrelated concepts. The aim of the research is to experimentally test how message recepients arrive at implicitly expressed meaning in advertisements. For that purpose an experiment focusing on one carefully chosen advertisement was conducted in which the examinees were asked to explain the meaning of the advertisement as well as to explain how they had arrived at that meaning. The examinees' answers were analyzed and interpreted with a special focus on the following issues: a) the linguistic and visual elements which prompted the examinees to reason in a certain direction, b) the ways in which the given linguistic and visual elements in the advertisement were elaborated into certain scenarios on the basis of extralinguistic, i.e. encyclopedic knowledge, and c) the spotted analogies between the logically unrelated elements in the advertisement. The main hypothesis was that the cognitive mechanism of conceptual integration is at the back of interpreting meaning. Thus, the Theory of Conceptual Integration was applied to the analysed data obtained in the experiment. The analysis showed that the elements which the examinees spotted in the advertisement, whole scenarios which they built from them, analogies and mixed mental pictures correspond to the elements, relations, mental spaces, mappings, projections and blended spaces in conceptual integration.

Key words: indirect advertising, communication, meaning construction, conceptual integration

\section{DODATAK}

\begin{tabular}{|l|ll|}
\hline \multicolumn{1}{|c|}{ Banka Inteza } & \\
\hline $\begin{array}{l}\text { Koja je poruka } \\
\text { (tj. značenje) } \\
\text { reklame? }\end{array}$ & $\begin{array}{l}\text { 1. } \\
\text { Naš novac može biti uvećan ako ga osiguramo u toj banci, tj. } \\
\text { predamo na čuvanje. }\end{array}$ \\
& $\begin{array}{l}\text { 2. } \\
\text { 3. }\end{array}$ & $\begin{array}{l}\text { Banka Inteza je idealno mesto gde će naš novac sigurno rasti. } \\
\text { zahvaljujući kamati koja je vrlo povoljna i privlačna za } \\
\text { klijente. }\end{array}$ \\
4. $\begin{array}{l}\text { Štedeći novac u Banci Intezi, mi zapravo imamo veliku } \\
\text { korist i naš novac "raste". Poruka je da će se banka } \\
\text { adekvatno brinuti o novcu, a mi ćemo od toga imati profit }\end{array}$ \\
5. $\begin{array}{l}\text { U ovoj banci, vaš novac će rasti, baš kao npr. vaše dete, i } \\
\text { "dostići" visinu žirafe. } \\
\text { Ako budete štedeli u našoj banci, bićete u plusu. }\end{array}$
\end{tabular}


7. Ako uložimo pare na tekući račun u toj banci, veće su nam šanse da dobijemo veću kamatu nego u drugim bankama

8. Banca Intesa je idealno mesto za otvaranje štednog računa $i$ štednju.

9. Banca Intesa je mesto gde se isplati se ulagati novac. Ima idealne uslove za rast.

10. Banca Intesa je idealno mesto za štednju

11. Štednjom u ovoj banci vaš novac sigurno raste, $\mathrm{tj}$. uvećava se.

12. U toj banci naš novac će rasti, odnosno, to je sigurno mesto za našu štednju.

13. Štednja u ovoj banci je najbolja.

14. U ovoj banci možemo da uvećamo naš novac.

15. Ukoliko stavimo novac u ovu banku, stanje na računu će nam rasti.

16. Banca Intesa je idealno mesto za štednju.

17. Ljudi vole novac, mnogo novca.

18. Ova banka je idealno mesto za rast i sigurnost našeg novca.

19. U Banci Intesa novac koji uložimo se stalno uvećava.

20. Novac se uvećava u ovoj banci.

Kako ste došli do te poruke?
1. Slika novčanice koja se poredi sa visinom žirafe, kao i lenjir, jasno ukazuju da je naglasak na rastu te novčanice, što je u prevodu uvećanje novca.

2. Slikom koju su upotrebili za reklamu, novac i dečiji metar.

3. Zahvaljujući službenici koja meri rast eura uz pomoć dečijeg metra sa likom žirafe. Originalno je, ali i prilično neozbiljno.

4. Službenica drži novčanicu kojoj meri visinu. Samim tim, novčanica je upoređena sa detetom, čiji se rast kontroliše.

5. Zbog slike koja pokazuje jedno od najviših živih bića na planeti, ali u obliku merača visine kojim se obično meri visina dece.

6. Do značenja se vrlo lako dolazi samim vizuelnim efektom. Novčanica od 100 evra koja "postaje" novčanica od 120 evra je veoma jasna slika.

7. Novčanica od $100 \mathrm{E}$ je narasla do $120 \mathrm{E}$, što dokazuje da treba da se ulaže u dotičnu banku.

8. Na osnovu novčanice, žene u poslovnom odelu, ali uglavnom na osnovu iskustva sa drugim reklamama tog tipa. 
9. Novac se meri metrom baš kao i deca, koja stalno rastu. Tako i klijenti ove banke mogu uvećati novac.

10. Novčanica se meri na dečijem metru za merenje visine. To znači da bi naš novac brzo narastao, tj. da bi mu se povećala količina, jer i deca brzo rastu.

11. Vizuelno ... Žena drži veliku novčanicu i meri je sa žirafom na kojoj su iscrtani centimetri i kao meri taj rast novčanice, tj. novca koji štedite.

12. Zbog toga što su upotrebili metar za merenje visine dece, koja brzo rastu. Deci treba sigurnost, a oni to svojim sloganom govore, da mogu da nam obezbede mesto za siguran rast našeg novca.

13. Tako što se novčanica, isto kao i dete, meri koliko je porasla.

14. Zbog slike žirafe, koja se koristi za merenje visine kod dece, i žene koja pokazuje kako je novčanica narasla od početnih 100 do $120 \mathrm{E}$.

15. Zbog slike novčanice koja se meri na vratu žirafe i koja može još da "raste".

16. Tako što bankarka meri novčanicu koja, po njenoj proceni, raste. To ukazuje na povećanje količine novca u banci.

17. Jer ima ogromna novčanica od $100 \mathrm{E}$ u reklami.

18. Na slici je žirafa, što označava rast, nešto visoko. Tu je metar, dečiji, pomoću čega merimo visinu dece, što označava neku sigurnost.

19. Na osnovu slike, jer je prikazana novčanica koju meri žena, $\mathrm{i}$ žirafa, koja predstavlja nešto visoko, odnosno kamatu.

20. Žena koja meri rast novca u odnosu na žirafu i reči "idealno mesto za rast vašeg novca".

Šta je neobično, nespojivo u reklami?
1. Neobično je da povećanjem same novčanice može rasti i vrednost koju ima, pogotovo to da može imati i približnu veličinu veličini jedne žirafe.

2. Neobične i nespojive su upravo te dve stvari koje su upotrebili, novčanica i metar.

3. Nespojivo je to što suu isti kontekst stavljeni službenica iz banke, koja izgleda kao pravi profesionalac, i dečiji metar sa likom žirafe. Ukazuje na jednostavnu poruku, koja bi trebala da se brzo prihvati. 
4. Neobično je što je uz novac upotrebljen glagol rasti, koji se najčešće odnosi na decu. To bi moglo da nas asocira na odnos banke prema svojim mušterijama. Oni se prema njihovom novcu odnose pažljivo kao prema deci.

5. Novac se upoređuje s decom, što ukazuje da će novac biti siguran i dobro čuvan, kao što bi se čuvalo dete.

6. Neobično je to što novac ne može fizički da raste.

7. Neobično je što se novčanica prikazuje kao stvar koja fizički može da raste, kao životinje ili ljudi. Žirafa pored novčanice pokazuje merilo rasta novčanice.

8. Nespojivo je to što novac ne raste i to što se upoređuje sa žirafom, jer ako se već govori o "rastu novca" nije bukvalno u visinu, vego u količini.

9. Poređenje rasta novca sa rastom deteta. Baš kao što su detetu potrebni dobri uslovi za rast, tako su i novcu, a Banka Inteza to obezbeđuje.

10. Nešto tako ozbiljno sa nečim tako neozbiljnim.

11. Personifikuje novac, poredi, tj. meri ogromnu novčanicu kao da meri rast deteta. Ukazuje da brinu o tom novcu kao o detetu.

12. Nespojivo je poređenje dece i novca. Novac ne može zaista da raste. Stvaraju negativnu aluziju na to da je novac bitan, koliko i deca i njihova sigurnost.

13. Novac ne raste i žirafica uopšte nije slatka. Više liči na magarca.

14. Žirafa i novac

15. Neobična je ideja spajanja novčanice, žirafe i merenja.

16. Novac i fizički rast.

17. Toliko novca na jednom mestu, povezanost vertikalnog rasta i evra, koji opada iz dana u dan.

18. Nespojivo je povezivanje novca, dece i životinje.

19. Novac, koji je skoro ženine veličine, i žirafa.

20. Žirafa, veličina novčanice.

Tabela 2: Odgovori ispitanika pri tumačenju reklame za Banku Intezu 